\title{
Research on the evaluation model of industrialization and information fusion based on D-FCE method -- Taking Xining Development Zone as an example
}

\author{
YangYang Shen \\ doubleyshen@126.com
}

(School of Management, Xi'an University of Architecture \& Technology, Xi'an, 710055, China)

Keywords: the integration of industrialization and informatization; maturity level; data envelopment analysis; fuzzy comprehensive evaluation

\begin{abstract}
Based on the improved maturity model of the integration Industrialization and informatization, this thesis uses the fuzzy comprehensive evaluation method on the base of data envelopment analysis and combines the quantitative analysis and qualitative analysis sufficiently to establish the maturity evaluation model of the integration of industrialization and informatization of Xining development zone. In addition, it evaluates the maturity levels of the integration of industrialization and informatization of the four parks in Xining development zone, namely, DongChuan, NanChuan, GanHe and biological science and technology. Finally, according to the evaluation model and its results, it puts forward some policy recommendations to the further development of each park in Xining development zone and the overall integration of industrialization and informatization.
\end{abstract}

\section{Introduction}

Xining economic and Technological Development Zone (after referred to Xining Development Zone) was founded in 2000, has built four Park. Dongchuan, biological science and Technology, Gan River, Nanchuan, with a total area of about 126.89 square kilometers, Investment enterprises more than 1100. In 2014 year, Xining Development Zone complete to the annual industrial production value of 28.2 billion yuan, accounting for $30.4 \%$ of Xining City ${ }^{[1]}$. Xining development zone plays an important role in the economic development of Xining city and the whole Qinghai province.

Many domestic scholars have studied the Integration of information and industrialization. Li Xingchen, Wei Ming from the fusion of the degree of hardness and fusion depth of three perspectives on the "Integration of information and industrialization" integration evaluation system ${ }^{22}$. Zhang Xin, Ma Jianhua using the analytic hierarchy process to evaluate the regional "Integration of information and industrialization" level of integration of ${ }^{[3]}$. Gong Bing Zheng of the fusion of the Integration of information and industrialization indicators and evaluation methods ${ }^{[4]}$ Yi Famin studied the degree of integration of " Integration of information and industrialization" in Guangzhou City $^{[5]}$. Hu Bing Study on the design and evaluation method of enterprise "two oriented" fusion index system of enterprise ${ }^{[6]}$. . Yang Lei published a paper based on the gray system of the "Integration of information and industrialization of the integration of maturity evaluation research," the concept of maturity is introduced into the integration of the "Integration of information and industrialization", and the use of gray system evaluation method ${ }^{[7]}$.In this paper, we establish the evaluation model of the integration of "Integration of information and industrialization" of the Development Zone, and evaluate the degree of integration of "Integration of information and industrialization".

\section{Maturity degree construction}

Development Zone "Integration of information and industrialization" integration of maturity, in order to achieve the development zone of the wisdom of the park construction, the Development 
Zone in the integration of industrialization and information technology to show the overall capacity. In the Development Zone, the integration of "Integration of information and industrialization" is divided into 5 stages: initial level, basic level, growth stage, mature stage and optimization stage. Each stage has characteristics of different maturity. The "Integration of information and industrialization" integration of the maturity level of the progressive structure and the level of standards are shown in Figure 1:

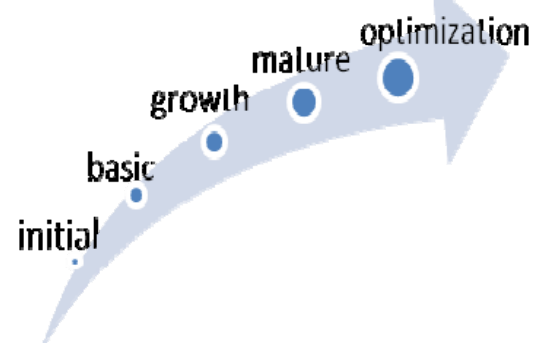

Fig. 1 level of Industrialization and information fusion

\section{The evaluation model of the three degree of fusion maturity}

Development Zone is a regional economy which takes the enterprise as the main body, and it must be based on the Integration of information and industrialization elements of the enterprise and the region in the evaluation of the "Integration of information and industrialization" integration of the development zone. In this paper, the development of the "Integration of information and industrialization" integration of the maturity evaluation model index is divided into three categories, a total of ten indicators. One of the indicators is divided into human resources, the integration of environment, the application level, the Integration of information and industrialization level indicators for the information input, the information of fixed assets, information input, the annual net profit, attention, infrastructure, research and development, process control, integration should be used.

\section{The method of evaluating model for the integration of maturity degree}

The basic idea of fuzzy comprehensive evaluation method based on Data Envelopment Analysis (D-FCE method) is that the evaluation results obtained from the data envelope analysis are used to evaluate the fuzzy comprehensive evaluation ${ }^{[8]}$.

\subsection{DEA performance of Fuzzy}

The results of the DEA evaluation are the results of the relative comparison among the units, and the numerical objective reflects the relative efficiency of each evaluation unit, and the result of the evaluation is more objective and convincing. However, the evaluation result of DEA is a single numerical value, and the subjective level of the fuzzy comprehensive evaluation is not available, so the membership function of fuzzy mathematics can be used to make the DEA score fuzzy, so that it can be unified with other indexes in subjective sense and performance.

Development Zone "Integration of information and industrialization" integration maturity is divided into 5 levels. $\mathrm{V}=(\mathrm{V} 1, \mathrm{~V} 2, \mathrm{~V} 3, \mathrm{~V} 4, \mathrm{~V} 0)$ in the evaluation of fuzzy comprehensive evaluation, the results of DEA can be understood as the degree of membership of these 5 levels. The fuzzy processing is carried out using the triangular membership function, as shown below.

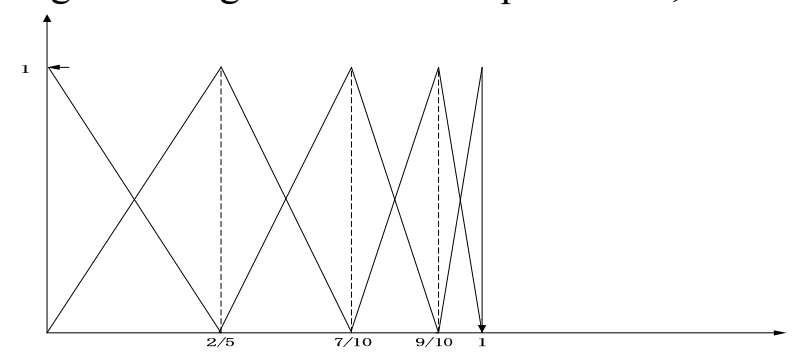

Fig. 2 Membership function of fuzzy evaluation 


\section{2 comprehensive evaluation}

The quantitative index has been calculated by the data envelopment analysis and the FCE results of the non quantitative index. Then, the next step is a comprehensive evaluation.

\section{Xining Development Zone, the five degrees of maturity evaluation.}

According to the method of this paper, the analysis of industrialization and informatization maturity of Xining Development Zone. Detailed information see Table 1 and Table 2.

Table 1 Specific indicators and corresponding data

\begin{tabular}{|c|c|c|c|c|c|c|c|c|c|c|}
\hline \multirow{3}{*}{$\begin{array}{l}\text { Index } \\
\text { Prop. } \\
\text { Index }\end{array}$} & \multicolumn{4}{|c|}{ Human resources } & \multicolumn{3}{|c|}{ Fusion environment } & \multicolumn{3}{|c|}{ Application level } \\
\hline & \multicolumn{4}{|c|}{0.2} & \multicolumn{3}{|c|}{0.4} & \multicolumn{3}{|c|}{0.4} \\
\hline & people & $\begin{array}{l}\text { Fixed } \\
\text { assets }\end{array}$ & input & profit & $\begin{array}{l}\text { Impor } \\
\mathrm{t} \\
\text {-ant }\end{array}$ & $\begin{array}{l}\text { Constr } \\
\text { u-ction }\end{array}$ & $\begin{array}{l}\text { Faciliti } \\
\text { e-s }\end{array}$ & $\begin{array}{l}\text { Develo } \\
\text {-pent }\end{array}$ & $\begin{array}{l}\text { Process } \\
\text { control }\end{array}$ & $\begin{array}{l}\text { Applicat } \\
\text {-ion }\end{array}$ \\
\hline Prop. & DEA & DEA & DEA & DEA & 0.2 & 0.4 & 0.4 & 0.2 & 0.4 & 0.4 \\
\hline D.C & 15.8 & 3717 & 3752.7 & 2687.8 & $\begin{array}{l}1,4,3 \\
2,0\end{array}$ & $\begin{array}{l}2,3,4 \\
1,0\end{array}$ & $\begin{array}{l}3,4,2, \\
1,0\end{array}$ & $\begin{array}{l}5,3,1, \\
1,0\end{array}$ & $\begin{array}{l}2,4,3, \\
1,0\end{array}$ & $\begin{array}{l}1,4,3, \\
2,0\end{array}$ \\
\hline N.C & 13.5 & 520 & 744.3 & 113 & $\begin{array}{l}2,5,3, \\
0,0\end{array}$ & $\begin{array}{l}2,4,3 \\
1,0\end{array}$ & $\begin{array}{l}3,4,3, \\
0,0\end{array}$ & $\begin{array}{l}5,4,1,0 \\
, 0\end{array}$ & $\begin{array}{l}4,2,3, \\
1,0\end{array}$ & $\begin{array}{l}3,3,3, \\
10\end{array}$ \\
\hline G.H & 14.3 & 2658.5 & 2698.3 & 1939.3 & $\begin{array}{l}1,4,4 \\
1,0\end{array}$ & $\begin{array}{l}2,3,4, \\
1,0 \\
\end{array}$ & $\begin{array}{l}3,4,2 \\
1,0\end{array}$ & $\begin{array}{l}5,3,2,0 \\
, 0\end{array}$ & $\begin{array}{l}2,3,4, \\
1,0\end{array}$ & $\begin{array}{l}1,4,4, \\
1,0\end{array}$ \\
\hline B.S & 15.1 & 3652.1 & 3701.1 & 2660.6 & $\begin{array}{l}1,2,4, \\
3,0\end{array}$ & $\begin{array}{l}2,5,2, \\
1,0\end{array}$ & $\begin{array}{l}1,2,3, \\
4,0\end{array}$ & $\begin{array}{l}5,3,2,0 \\
, 0\end{array}$ & $\begin{array}{l}2,3,3, \\
2,0\end{array}$ & $\begin{array}{l}1,5,3, \\
1,0\end{array}$ \\
\hline
\end{tabular}

Table 2 Comprehensive evaluation results

\begin{tabular}{|l|l|l|l|l|l|l|}
\hline & optimization & mature & growth & basic & initial & results \\
\hline D.C & 0.1892 & 0.1148 & 0.224 & 0.296 & 0.176 & basic \\
\hline N.C & 0 & 0.048 & 0.224 & 0.328 & 0.36 & initial \\
\hline G.H & 0.1998 & 0.074 & 0.272 & 0.28 & 0.176 & basic \\
\hline B.S & 0.2 & 0.152 & 0.224 & 0.28 & 0.144 & basic \\
\hline X.N & 0.147 & 0.097 & 0.236 & 0.46 & 0.214 & basic \\
\hline
\end{tabular}

\section{Conclusions and recommendations}

Based on the above analysis, the calculation, we can draw the following conclusions: (1)from the table 4 data can be seen, Dongchuan, Gan River, biological technology and maturity level evaluation basic level data were $0.296,0.28,0.28$, three industrial parks belong to basic level. Nanchuan Industrial Park maturity evaluation initial data is 0.36 , so the Nanchuan Industrial Park belongs to the initial stage. Nanchuan Industrial Park compared to the other three industrial park in integration of the Integration of information and industrialization is relatively backward stage, industrialization and informatization are no advantage,"Integration of information and industrialization integration maturity seriously lagging behind. Four industrial parks of Integration of information and industrialization fusion maturity from high to low are biological science and Technology Garden > Ganhe > Dongchuan > Nanchuan.(2) the Xining development zone is in the basic stage of the integration of "Integration of information and industrialization". There is still a great distance from the optimization stage.

\section{References}

[1] Xingxin Nie. Xining economic technology development district "depth of industrialization and information fusion" program [R]. Xi'an: Xi'an University of architecture and technology.2014.

[2] Ming Wei, Xingchen Li. Two assessment system for the integration of [J]. Xi'an University of Posts and telecommunications, 2014 (1):103-110. 
[3] Xin Zhang, Jianhua Ma. Evaluation method and application of regional integration of two [J]. Journal of Shandong University, 2012 (3):71-96.

[4] Famin Yin. The integration of information and industrialization in China and its evaluation system research [D]. Tianjin University, 2010

[5] Bingzheng Gong. Study on the integration of information and industrialization of [J]. Chinese information industry, 2008 (1) :52-55.

[6] Bing $\mathrm{Hu}$. Research on the design and evaluation method of the two enterprise integration index system [D]. Tianjin University, 2011 (11).

[7] Lei Yang. "Two fusion" maturity evaluation based on gray information [D]. Nanjing University of Aeronautics \& Astronautics, 2013

[8] Shun Liu, Shuxin Du. Fuzzy comprehensive evaluation method based on data envelopment analysis [J]. fuzzy systems and mathematics, 2012 (4):93-98. 